\title{
Navigating Service Sector Innovation using Co-creation Partnerships
}

\author{
Stephen Burdon, Grant Mooney, Hiyam Al-Kilidar \\ School of Systems, Management and Leadership, University of Technology, Sydney
}

\section{Keywords}

Customer satisfaction; innovation; collaboration; co-creation; competitive advantage; service; partnership; alliance.

\begin{abstract}
Purpose - This paper analyses a series of engineering services partnerships to better understand requisites needed in building high value co-creation alliances - especially where innovation is the strategic goal.

Methodology/approach - Using a combination of quantitative surveys, qualitative 'deep-dive' assessments and a small number of in-situ mini-case investigations this research sets out to analyse 99 joint-venture innovation partnerships. These ventures represent a variety of asymmetric and symmetric alliances within the engineering services sector. Particular emphasis is given to those where the prerequisites for cocreative innovation are either in place or could be built.

Findings - Partnering and progressing innovative ideas are important behaviours for organisations seeking higher levels of commercial success and competitive advantage. Navigating the partnering dynamic can also be harder than expected, potentially hindered by misunderstandings and differing expectations between enterprises. Particularly for symmetric endeavours success often hinges upon not only having clarity in the degree of innovation sought but also alignment as to the depth and stage of the partnering dynamic itself. However, when such collaboration works customer satisfaction and associated contract retention can increase significantly.

Originality/value - Most inter-company innovation projects historically seem to occur where one firm is significantly larger than the other. In contrast, this study highlights issues encountered when innovation co-creation projects are undertaken by a mature (as opposed to maturing) organisation in collaboration with partners where the power balance is similar between the two enterprises. In such cases, customer satisfaction surveys can be useful tools for objectively navigating the innovation co-creation experience.
\end{abstract}

\section{Introduction}

Innovation is often identified as a driver of commercial growth within both individual businesses and the wider market economies of which they form a part (AON Hewitt, 2012; Czuchry et al., 2009; Dershin, 2010; Gumusluoglu and Ilsev, 2009; Waychal et al., 2011). However, as markets have matured there has been evolution in the way such innovation is often conducted.

Traditionally, in the search for the 'first-movers advantage' (and potential early preeminence within an industry segment) firms would seek break-through innovation as a means to surpass rivals. In the majority of cases this was a closed process (Antikainen et al. 2010). With developer organisations asserting rights to secure intellectual property and compartmentalise important knowledge, customers were often relegated to a passive role as an income-stream to be tapped rather than a 
partner to be actively consulted. Even when concepts were jointly developed it was usually the service providers that took title to the IP with customers simply receiving preferential licensing arrangements.

However, in the last 10 years, technological advances and economic upheavals have given rise to new entrants, putting pressure on traditional business models and timehonoured behaviours. Encouraged by increasing competition, established services firms have tried to hasten innovation delivery by being more open to partnering with other entities holding useful resources or complementary skill sets. Aligning with customer organisations seems a natural fit for such efforts.

This paper highlights the collective experience of co-creation ventures established between customer and engineering services provider to progress innovative outcomes. The research supports Chesbrough and Appleyard (2007) investigations around open innovation as well as building upon Prahalad and Ramaswamy (2004a) work on cocreating value. Our research objectives include:

i) Identifying key lessons to be learned when service provider and customer organisations partner for high-value co-creation initiatives;

ii) Better understanding the relationship between inter-enterprise collaboration and likelihood of innovation emergence (especially when embedded within a symmetric power dynamic).

Historically very profitable, the engineering services sector has more recently seen increased competition and commoditisation of offerings. This prompted one organisation, XYZ, to experiment with more collaborative styles of engagement. Multiple customer/provider alliances were established over a number of years and at preset intervals the key partnering ventures were assessed.

There were some significant revelations. In enthused partnerships very positive outcomes can be attained given the right enabling. There are also risks for decisions made upon relationship assumptions. For partnership alliances internal satisfaction ratings can be an indicator of relationship health, an early warning system for danger and possible telegraph for innovation emergence.

\section{Literature Review}

\subsection{Understanding Innovation}

Presence of innovation has been repeatedly identified as a major common denominator of successful organisations (Piperopoulos and Scase, 2009; Vaccaro et al., 2010; Borjesson and Lofsten, 2012). For example, a recent study by AON Hewitt (2011a; 2011b) comprising over 180 international organisations and subsidiaries reported the consistently superior financial performance of the more innovative companies. They found enterprises actively engaging and promoting innovative behaviours averaged 38\% higher return on investment and 22\% higher gross margin than more traditional counterparts. Similarly, research by Jaruzelski et al. (2011) suggested organisations with cultures highly aligned to innovation requisites have $30 \%$ higher enterprise value growth than rivals. With these numbers it is easy to see why "corporate executives often bet the future of billion-dollar enterprises on an innovation” (Christensen and Raynor, 2003, pp.7).

However, while the link between successful innovation and competitive advantage is widely recognised real-world efforts to enact it can easily misfire. Christensen (Christensen et al., 2003), a respected authority, points out that innovation is not a- 
one-size-suits-all process simply adopted off the rack. Similarly, Foster and Kaplan (2001) note that innovation can come in multiple types requiring different prerequisites:

- Incremental innovation

Representing small and continuous improvements to products, processes and services (Dewar and Dutton, 1986; Nair and Boulton, 2008), incremental innovation is necessary to ensure enterprise offerings stay current and relevant.

- Radical innovation

Modifying marketplace economics and displacing current product lines in favour of entirely new categories (Lewrick and Raeside, 2010) radical innovation often signals a business paradigm shift. An example would be passenger by-passing of travel agents to internet-book flights for themselves.

- Transformational innovation

Transformational innovation is a historic and irreversible change in the way of doing things. Altering the future by moving to new ways of thought, not just product, it modifies the cultural paradigm by "learning of a new modus operandi...coupled with a vast amount of unlearning of past modus operandi" (Remneland-Wikhamn, 2011, pp.725). An example would be the societal changes brought about by introduction of mobile cell phones.

While the innovation debate is more complex than such high-level segmentation suggests, it can be useful to think of it in these terms. Tracing success for the different types posits their emergence is increasingly relationship and collaboration dependent: Vermeulen et al. (2010) discuss how shifting organisational dynamics fosters ingenuity; Dyer et al. (2009, pp.22) note how decision makers gain vital perspectives “associating, questioning, observing, experimenting and networking”.

Positive interactivity seems to be a recurring theme when discussing innovation delivery - and this is also where the concept of cross-organisational collaboration needs to be introduced to the debate. If innovation is a strategic goal, and human cooperation is instrumental to that outcome, then it seems logical that the wider the capability pool the higher the potential of revolutionary outcomes. Orchestrating whole enterprises, not just individuals, to productively work together could generate unexpected gains. However, there is also a corollary implicit in the definitions above, namely that while incremental innovation can be built upon traditional management and partnership structures, radical and transformational categories posit the need for new approaches. Co-creation, an extreme form of enterprise collaboration, is thus arguably a radical/transformational-level modus operandi.

\subsection{Enterprise Collaboration, Co-creation and Innovation}

Traditionally the role of customers in the economic landscape was one of passive product recipients at the end of a value chain - and particularly notable for their absence from innovation models (Grabher et al., 2008). However, increasingly, provider organisations are realising that allying with customers as partners, not just consumers, can unlock fresh experiences and new sources of competitive advantage.

For example, Faems, Looy et al. (2005) explored the behaviours and performance of 221 EU manufacturing firms to better understand how inter-organisational collaboration impacted the effectiveness of innovation strategies. Their study 
confirmed a positive link between collaboration and innovation performance and strongly recommended inter-organisational cooperation with customers when seeking to encourage product or service originality. Others reinforce this view: Desouza et al., 2008; Mustak et al., 2013; Koen et al., 2011; Denning, 2010; Giesen et al., 2010; Di Gangi et al. (2010) - all attest to the drive for direct customer involvement in innovation activities. Blumenitt (2004, pp.29) highlights an additional interesting corollary by saying this is "especially true for firms in mature or declining industries".

In fact, business trends suggest that the nature of commercial competition is evolving away from individual company rivalry towards one of contending alliances. This is a reality where "firms take part in end-product supply networks that compete against alternative end-product networks” (Chapman and Corso, 2005, pp.339).

These two concepts - (i) customers as innovation partners; and (ii) rise of competing enterprise coalitions - puts a spotlight squarely on consumer-provider interaction as a basis for future worth. Prahald and Ramaswamy (2004b, pp.7), researchers in the cocreation area, suggest that forging partnership networks and deftly navigating the resulting co-creation dynamic, "where the roles of the company and the consumer converge", will increasingly become known as characteristics of commercial success for the $21^{\text {st }}$ century. They also stress the need for building what they term 'innovating experience environments' as opposed to narrow pursuit of demand-side improvements to products and services. True co-creation for innovation goes beyond simple contract fulfillment to crafting networked mindsets behind a new locus of value.

\subsection{Issues of Partnering, Symmetry and Existing Research}

While benefits of inter-firm collaboration appear sound taking advantage of wider pools of capability requires effective practices to mediate linkages (Foss et al., 2011; Gebauer et al., 2010). Such mediation may not be easy when partnerships are poorly constructed, interests conflict or dissimilar organisation cultures are involved. For example, Enkel et al. (2005) discuss SIG allCap's cooperation with a customer in developing an innovative concept only to have the customer take the jointly developed know-how to a rival provider; Hansen (2009) mention problems with collaborative focus when profit and cash-flow returns don't immediately materialise; Antikainen et al. (2010) cite heterogeneity when innovations developed in a close relationship with one customer are too selective to appeal to wider masses. Other dangers include conflict over IP, demand for unique rights, imbalanced risk/reward, use of legal jurisdictions and so on. Co-creation can produce value but success should not be assumed.

Two other points around extant literature of innovation co-creation are worth noting.

First, the majority of published cases seemingly describe asymmetric relationships where one partner significantly outweighs the other in terms of enterprise influence or authority (Muthusamy and White, 2005). In such examples innovation 'collaboration' or 'co-creation' may well see the weaker entity being little more than an idea and resource feeder system for a larger associate who then "exploit its asymmetric power to maximize its own benefits" (Xu and Beamon, 2006, pp.8). Comparatively little seems written regarding lessons of inter-organisational co-creation when partnering entities are symmetric, owning similar influence, power, resources and/or industry clout. Where literature does consider balanced relationships it is often in the context of devising theoretical frameworks (e.g. Mentzer et al. 2000) or drawing upon examples now somewhat dated (Kumar et al. 1995; Buchanan, 1992). However, such 
sources, though lesser in number, do suggest a connection between partner symmetry and increased ability to realise a strategic performance - a theme worth exploring.

Second, while innovation collaboration is topical most researchers seem to focus primarily upon manufacturing, product delivery and/or financial contexts. Service sector innovation and partnering, in contrast, seems to get much less air-time: "a recent comprehensive review of the academic literature...reveals little explicit coverage of research on service innovation” (Sampson and Spring, 2012, pp.42).

Richer review of co-creation would be of value - especially when narrowed to service sector innovation and sourcing of customer viewpoints (Payne et al, 2008). At the very least, with growth in service markets and trends towards collaborative business there appear good grounds for closer examination.

\section{Research Methodology}

The research explores alliance ventures between a major engineering services provider and a number of customer organisations. In conjunction with these, the researchers helped design and administer a 'Health of Relationship' (HoR) survey primarily to better understand the partnering dynamic between service provider and customer but with particular attention on ability to co-create innovation.

The XYZ organisation was chosen as it is a leading engineering services company in a $\$ 30$ billion Australian market. It employs a partnering business model to provide maintenance, operations management and capital project services to a wide range of market sectors. The value of each alliance varies from tens to hundreds of millions of dollars but each have the common raison d'etre of achieving collective efficiencies and benefits beyond the previous, and usually in-house, arrangements of their parent enterprises. Average partnership age is approximately six years (although many have been in existence much longer) and as they mature, higher value outcomes are expected to justify each service venture's continued existence. While most of these 'co-creation' endeavours include innovation among their formation objectives, functional approaches are generally left to individual alliances - thus presenting a good variety of originality-seeking collaborations from which to source data.

Our research approach comprised three phases. An initial survey to partnerships identified the relative importance of innovation compared with other requirements. After analysis of initial results three mini-case studies were undertaken to more closely validate these outcomes in-situ. A final 'deep-dive' study was then designed to focus upon aspects of creating innovation within partnership subsets. Although primarily leveraging qualitative results from the focus-area deep-dive this paper selectively summarises and discusses aspects of all three levels.

\subsection{Quantitative Survey}

Initially a 5-point likert satisfaction survey was employed covering questions in relation to ventures over 12 categories (drawn from a combination of previous HoRs, customer-suggested priorities and contemporary engineering services literature):

1. Management performance;

2. Access to, and approachability of, the management team;

3. Communication between partner staff;

4. Understanding of venture purpose (goals, requirements, business drivers);

5. Alignment between partners (goals, requirements, business drivers, KPIs); 
6. Bringing of new ideas and practices to the venture through innovation;

7. Responsiveness of the venture (to change, internal/external imperatives, etc.)

8. Provision of service;

9. Effectiveness of venture processes, strategies and outcomes;

10. Quality of venture processes, strategies and outcomes;

11. Skills, training and value of venture staff;

12. Venture Occupational Health and Safety (OH\&S).

Staff within the joint-ventures were asked to rate both overall performance of their operation and, more specifically, management and outputs. Survey participants were taken from four groups seconded to ventures from their respective parents:

- Customer management team;

- Customer operation team;

- XYZ management team;

- XYZ operation team.

Of particular note for this research paper were questions posed within the innovation area regarding a partnership's ability to effect new ideas and work practices by:

- Developing existing strength through incremental improvement;

- Realising a strategic leap that creates new outcomes with mutual benefit.

Thus, views of the partnership and innovation type/value were sourced from multiple levels. For each offspring entity demographic data was also collected:

- Venture industry sector;

- Size of each parent organisation (i.e. by revenue and number of employees);

- Size of contractual commitment by each parent organisation to the jointventure;

- Significance of deliverables to parent organisations (i.e. operational, tactical or strategic).

In total, 99 co-creation ventures were surveyed. All questionnaires were administered, and data collected, by independent third-party to preserve respondent anonymity and enable honest reporting. Demographic data allowed responses to be grouped based upon Muthusamy and White (2005) definition of inter-organisational power relations:

Symmetric - Both parties possess similar ability to affect the decisions of the other

Asymmetric - One party has greater control/influence than the other

For the above, relatively analogous parent revenue, employee numbers and alliance venture financial commitment were employed as determinants of 'ability to affect the decisions of the other' during data segmentation. Correlation of data sets occurred over the 12 areas of performance of which innovation, as a key focus, was one.

\subsection{Mini Case Studies}

Three customer organisations with strong reputations for innovation were chosen. Via a number of semi-structured interviews with key personnel, this stage of the research sought to selectively affirm outcomes of the quantitative survey; explore approaches to co-created innovation; and refine preparation of the upcoming deep-dive.

Case 1: Oil/Gas (Singapore Refinery Company)

This organisation holds a global reputation for building superior innovation culture coupled to ability to co-create through partnerships. It was chosen to explore key requisites in these areas including collaboration, commitment, 
vision, core competencies, development processes and training.

\section{Case 2: Steel Manufacture/Prefabrication (Bluescope Steel)}

A leading flat product steel producer it has over twelve years' experience in managing high-value inter-organisation partnerships. During that time it has also demonstrated capability for building transformational innovation via cocreation activities.

Case 3: Telecommunications (Telstra)

This organisation is the leading Australian telecommunications operator with significant expertise in converting commodity supply relationships into high value partnerships. Using their high level service alliance skills, they have benefited their wide customer base by radically improving systems, cost structures and customer services

\subsection{Qualitative Survey}

Once initial quantitative results had been evaluated then deeper investigations regarding innovation practices, processes and behaviours could be progressed.

Partnership ventures contributing to the primary survey and professing innovation as a priority were again approached to participate in a qualitative focus-area ('deep-dive') study. 41 entities were included in this round - 21 meeting the criteria for symmetric alliances with remaining entities judged asymmetric. Open-ended questions were initially put to staff within all 41 ventures:

1. How would you assess the number, quality and success of ideas advanced from the venture in the last 12 months?

2. Of the ideas advanced, how would you categorise them? (innovation definitions using incremental, radical and transformational concepts proposed by Foster and Kaplan (2001) were supplied)

3. In what areas, if any, do you believe the venture should focus its attention in developing radical ideas?

4. In what areas, if any, do you believe the venture should focus its attention in developing transformational ideas?

5. Specifically, in which areas of service delivery would you seek innovation improvements? (suggested sectors were supplied as evidenced from the earlier quantitative survey)

Feedback at this step was more free-flowing and participants could respond in their own words, add information and provide personal opinion. Data coding of response content was aligned to segmentation resolved from the quantitative study (see 3.1) plus additional sub-themes emerging independently from the case studies and deepdive itself (e.g. idea generation/assessment, internal culture, ability to collaborate, loyalty, vision, staff motivation, skills capability, enabling practices, resourcing). Minor vetting of output was done to maintain anonymity.

Moving from broader quantitative aspects of innovation partnering to more qualitative examination of repeated themes permitted deeper review and data cross-correlation. Results of earlier HoR iterations going back to 2004 were also examined to appreciate shifts in service interests over the last decade.

\section{Data Analysis}


Data from the research was extremely rich, necessarily imposing limits upon what could reasonably be covered within a single discussion paper. Treatment will, thus, be limited to three key perspectives (and their implications) as generated from the study:

- Joint-venture satisfaction levels were analysed over 12 areas including an innovation segment (see 3.1). This gave an overall satisfaction rating plus correlation of how producing innovative results influenced partner perspectives.

- Customer-side and provider-side views were analysed to determine degree of alignment exhibited by the joint entities during project life.

- Perceived capability to evoke radical/transformational ideas (i.e. above those supporting a simple incremental scope) identified where the reality of service innovation, partner expectation and co-creation became visible.

An outline of these elements follows.

\subsection{Satisfaction with Co-creation Outcomes}

Data from this research (Figure 1) shows that most customers within the 99 joint projects initially reviewed had expectations met or significantly exceeded. On a standalone basis these results seem reasonable. It is only when compared to historical results going back over five years that a change in satisfaction has clearly occurred. The difference centres on two areas: a reduction in the number of customer-partners for whom expectations were 'significantly exceeded'; and an increase to 25\% of partners saying they received benefits below expectation from collaborative activities.

Drilling down into innovation-specific data revealed lower than anticipated scores from projects for which this was a focus. At the high end of the scale $20 \%$ of customers felt they had received innovative solutions exceeding expectations; at the lower end approximately 37\% of ventures indicated innovation benefits fell below or significantly below where they needed to be (Figure 2). As innovation and futureproofing were well-publicised strategic rationales for XYZ and customers in forming many of the co-creation alliances these numbers highlighted unacknowledged issues with enablement and delivery.

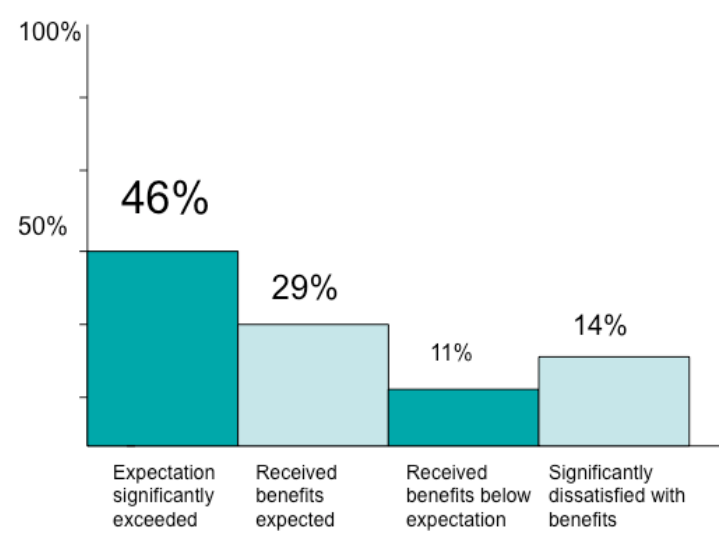

Figure 1: Overall satisfaction regarding the cocreation venture

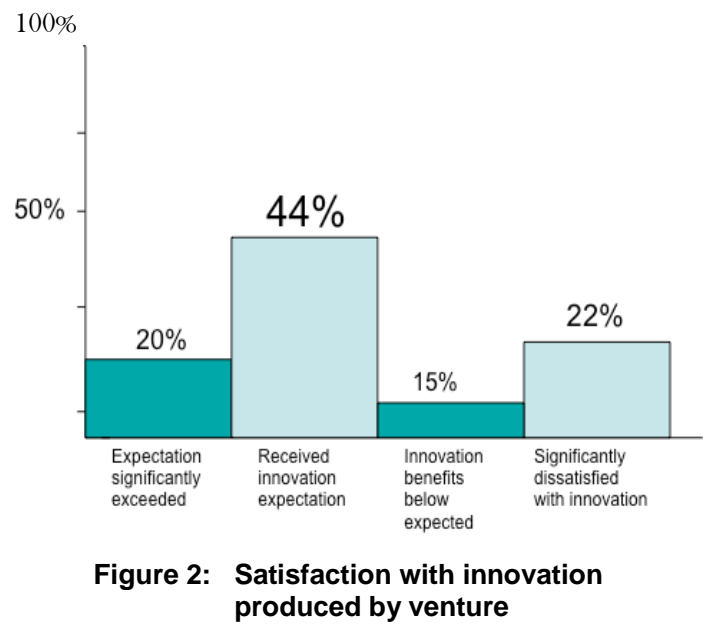

Decline in satisfaction can be better appreciated in the light that, historically, $96 \%$ of XYZ customers renewed contracts upon expiry. However, by 2011/2012 only 85\% were re-signing - a significant change for any services business. 
Looking at less satisfied customers, and summarising views underlying their dissatisfaction, most reasons can be placed into three categories:

1. Commoditisation of previous competitive advantages

Businesses are more aggressive and the historical differentiators have been eroded. As the number of operators in the service sector increases the challenge is to sustain a unique value proposition in a landscape replete with a wide array of price-competitive alternatives. Simply ‘doing a good job' as a service provider is no longer sufficient to maintain customer loyalty.

2. New expertise and learning needs to be developed

Long-term customers already incorporated significant operational efficiencies so realising additional benefit relies upon creative effort by partnerships in building new products/services streams. These often stepped outside business frameworks where XYZ was most familiar so their ability to guide partnerships towards fresh value (as expected by customer-side staff of service colleagues) was affected. This research provided empirical evidence of why XYZ needed to refresh its business model, delivery skills and management acumen if it was to truly satisfy customers of its ability to engage and co-create innovation beyond minimum levels.

3. Assumptions within ventures

In the asymmetric ventures studied the weaker associate would often find itself attempting to accommodate the mindset of the stronger. Expectations (and differences therein) for the most part were clarified relatively early. However, for the 21 symmetric ventures the qualitative responses suggest that visible similarity between parents could prompt operational (and unarticulated) assumptions within joint teams, especially when explicit detail was low. This had implications for satisfaction ratings when divergence in views inevitably came to light.

While the first two points above support other research into innovation and cocreation (Prahald and Ramaswarmy, 2004b; Payne et al, 2008) the third finding, although logical, appears new in the context of jointly creating a locus of value. Surface similarities between symmetric organisations can mask deeper-lying dissimilarities in operational style not immediately obvious - tripwires for later dissatisfaction within partnerships. With potential loss of contracts and impacts upon inter-organisational relations there can be consequences attached to not managing codevelopment opportunities effectively. Even long-established alliances cannot be taken for granted when service perceptions falter (Juga et al., 2010).

\subsection{Alignment of Co-creation Expectations}

One of the more useful research aspects came from examining the views of XYZ site managers/workforce compared with equivalent customer representatives seconded to the 99 ventures. Specifically, this component regarded how well customer needs were communicated, verified and mutually understood within the partnering dynamic before applying the following segmentation:

- Scores within 5\% of each other show service provider and customer share understanding and are on a common wavelength within a partnership;

- $5 \%$ to $10 \%$ difference meant there is significant misalignment;

- $10 \%$ to $20 \%$ difference is major and serious misalignment;

- Over $20 \%$ indicates there is no alignment. 
Lendrum (2000) and other researchers postulate that differences in the $5 \%$ to $10 \%$ band are a major impediment to progress while any score over $10 \%$ effectively signals no progress is likely until a more common view is formed. With this in mind a breakdown of results for ventures examined is shown in Table 1 (numbers rounded).

\begin{tabular}{|c|c|c|c|c|}
\hline Alignment Grouping & $\begin{array}{c}\text { Good } \\
\text { Understanding }\end{array}$ & $\begin{array}{c}\text { Significant } \\
\text { Misalignment }\end{array}$ & $\begin{array}{c}\text { Major } \\
\text { Misalignment }\end{array}$ & $\begin{array}{c}\text { No } \\
\text { Alignment }\end{array}$ \\
\hline XYZ to Customer Managers & $34 \%$ & $15 \%$ & $46 \%$ & $5 \%$ \\
\hline XYZ to Customer Workforce & $51 \%$ & $15 \%$ & $34 \%$ & $0 \%$ \\
\hline
\end{tabular}

Table 1: Service provider understanding of (and alignment to) customer needs within ventures

There are interesting outcomes from this overall analysis. First, manager understanding of customer needs and whether these were being met is much less in tune than those of the workforce: $34 \%$ versus $51 \%$. Second, the degree of significant misalignment (or worse) of provider managers and seconded staff to their customer equivalents is much higher than expected: $66 \%$ and $49 \%$ respectively.

When the same exercise was undertaken specifically in regard to the 41 innovationdriven partnerships the results were even more striking.

\begin{tabular}{|c|c|c|c|c|}
\hline Alignment Grouping & $\begin{array}{c}\text { Good } \\
\text { Understanding }\end{array}$ & $\begin{array}{c}\text { Significant } \\
\text { Misalignment }\end{array}$ & $\begin{array}{c}\text { Major } \\
\text { Misalignment }\end{array}$ & $\begin{array}{c}\text { No } \\
\text { Alignment }\end{array}$ \\
\hline $\mathrm{XYZ}$ to Customer Managers & $8 \%$ & $40 \%$ & $38 \%$ & $14 \%$ \\
\hline $\mathrm{XYZ}$ to Customer Workforce & $23 \%$ & $25 \%$ & $32 \%$ & $20 \%$ \\
\hline
\end{tabular}

Table 2: Service provider understanding of (and alignment to) customer need for innovation within ventures

Only 8\% of provider-side managers had a good grasp of their customer's need for innovation and what might be entailed in delivery. The qualitative responses further expand upon this by suggesting the need for shared clarity and mutual qualification to avoid misconceptions and undiagnosed differences in expectation. One symmetric customer-side respondent highlighted: "need clear understanding of what innovation is between [XYZ] and customers"; a representative from the provider-side countered with the requisite "to find the right clients to work with for big ideas". A common language, a means to synchronise mindsets and explication of expectations would seem essential in co-creation ventures - especially when strategic levels of innovation are a premised reason for their formation.

Analysis of the research data very clearly indicated severe communication and alignment problems existed between partners in a majority of ventures.

\subsection{Views of Ability to Address Innovation within Co-creation Projects}

As the life-cycle of partnerships evolved, customer demand for new and far-reaching approaches became more prominent.

First, from the earlier literature review it seems logical to divide innovation into categories of incremental, radical and transformational. Using these designations and summarising the data, $67 \%$ of customers responding to the initial survey believed that collaboration delivered good, even superior, incremental-style innovation. This was clearly one of XYZ's strengths as a service partner - they were well skilled, cost effective and owned a proven record for step-wise improvement. However, with growing interest from many customers for exploring radical and/or transformational opportunities it appeared clear XYZ was not best prepared for such a noted departure 
from its existing norms, even within the joint-ventures. A number of the co-creation projects mentioned items such as "no process to discuss ideas" and "the process for sharing innovation ideas is, to say the least, painful". Although not universal, such comments more readily seemed to appear in symmetric endeavours - and often sufficiently late into planning/development cycles that corrective, rather than preventative, action was needed.

Second, as mentioned in 4.1, results indicated the partnering business model had grown towards commoditisation. Redeveloping competitive advantage would require not only updating and improving the generic service offering but, at least for the more important cases, greater use of customised approaches and specifically tailored solutions. The deep-dive outputs suggest customer-partners translated this thought in terms of projects providing more radical styles of innovation while XYZ mostly presumed use of an incremental modus operandi. As 'personalised and tailored experiences' is a key tenet of co-creation (see Table 3) a desire for more distinctive outcomes should have been exposed much earlier in some association lifecycles. Again, the expectations and assumptions gap between partners is visible.

Finally, in looking back to previous years and earlier HoRs customers had wanted ideas they could cultivate themselves. Conversely, the latest data showed a significant shift as customers now desired new concepts that could be advanced and developed as part of co-creation collaboration. They also expected XYZ to take lead in formulating these based upon their global experience, monitoring of technology advancements, interaction with other enterprises and so on. However, 59\% of current joint-ventures reported that XYZ did not present substantive ideas to the co-creation partnership during its lifespan beyond those routinely needed for meeting a nominal service contract scope (i.e. incremental improvements). As contract length is usually 3 to 6 years this means that radical or transformational proposals suggested by XYZ within joint ventures (as opposed to actually undertaken) averaged only about 1 for every 10 projects annually - a quite small number.

When such ideas were put forward approval ratings from associated customer-side partners jumped significantly. Of ventures receiving radical/transformational ideas for consideration $87 \%$ of customer-side staff were encouraged to rate XYZ as having good, very good or excellent performance. These highlighted the importance of balancing operational capability in delivering new ideas with creativity and imagination needed to fuel their conception.

Interestingly, both the best and worst results for generating radical/transformational levels of innovation came from the symmetric alliances. In one venture judged successful, a respondent simply suggested being open to asking the question "what wildly different things could we do here?" made the difference. Clearly, this was an entity where strong internal culture and good intrinsic understandings had developed. Alternatively, with one of the less successful ones, strong indications of mixed messages and an 'us-and-them' dynamic were present - as one provider-side staffer commented regarding a venture's inability to deliver desired outcomes "many clients that scream the loudest for innovation are the same ones who stifle it through their own processes and systems”.

\section{Learnings from Case}

There were significant lessons gained from the study. 
First, success of co-creation cannot be assumed simply because two organisations decide to work together. As suggested by Figure 3 partnering relationships progress through multiple generations from traditional service outsourcing, to trusted collaboration partnering and finally strategic joint engagement (Burdon et al. 2009).

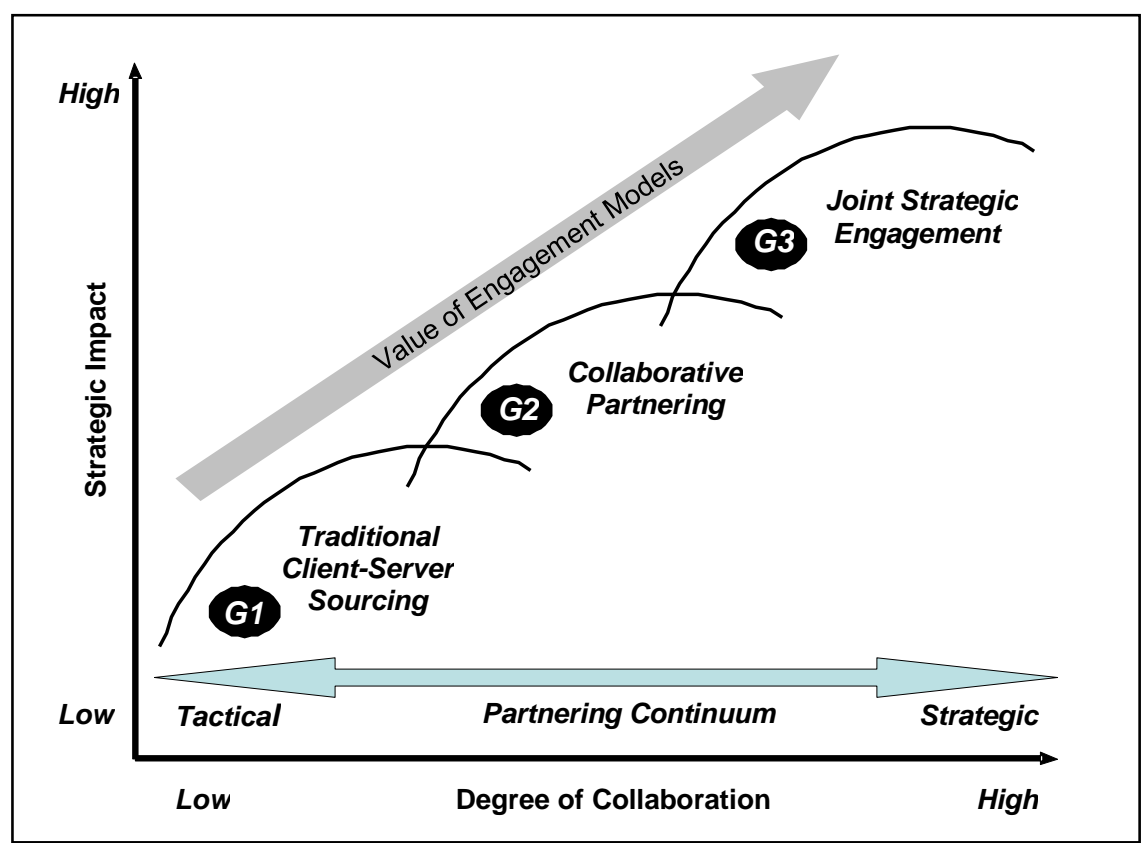

Figure 3: The three generations of service partnering relationships

Compare this to Prahalad and Ramaswamy (2004a, 2004b) statement of requisites for defining a co-creation venture as noted in table 3.

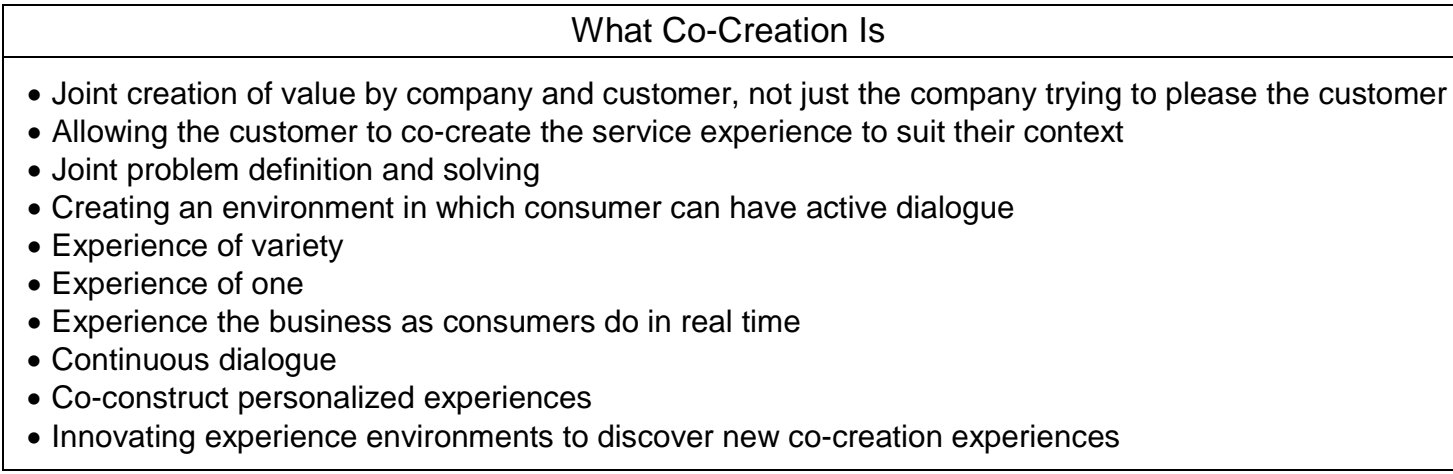

Table 3: The concept of co-creation

Co-creation clearly requires alignment of vision and supporting processes, and the development of advanced inter-organisational collaboration skills more suggestive of the later generations of partnering relationships. Organisations need to understand where their current relationship fits within the maturation life-cycle and deliberate investment needs to be made in maintaining relationship health - "find[ing] a way to connect people" as suggested by one joint-venture project manager. It was evident from the research results that while some ventures had the potential to develop cocreative initiatives others were in an earlier partnership stage.

Second, respondents commented that parent organisations' agreeing "a contract that is prescriptive in nature" doesn't give those on a joint team a sense of community or shared purpose but instead "stifled the area of new ideas and being innovative". 
Bound by product-delivery (and parent-centric) ethos, some venture teams indicated that the more bold the idea proposed the more risk management bureaucracy could be attached. Thus, 'innovating experience environments' suggested by Prahalad and Ramaswamy (2004a, 2004b) as a co-creation platform could inadvertently be annulled by partner self-protection. This finding also supports open innovation theory where freedom to experiment and reducing barriers to communication is more likely to prompt results: "innovative organisations systematically... encourage questioning, observing, networking and experimenting by employees” (Dyer et al., 2011, pp.8).

Third, the research suggests most customer-side partners want radical and transformational innovation opportunities to be explored not just incremental. This includes new models for staff involvement, commercial planning, organisation and systems management that challenge business-as-usual norms. This supports Jaruzelski et al. (2011) where they suggest that innovating for added-value beyond a minimum measure has become a serious desire for customers investing in service relationships. However, from our study, innovation delivery, as opposed to desire, often reflected the status of the inter-enterprise service relationship. While some partnership ventures were well placed to develop transformational offerings others were hampered by the requisite to develop a shared sense of identity largely separate from parents. On one project a respondent commented "it seems we want to have an innovative culture without the cost". Ostensibly, the type of innovation sought should be attuned to the stage of alliance relationship driving it.

Fourth, in symmetric partnerships the inclination to make assumptions can be a potential concern. While assumptions also occur in asymmetric relationships these appear susceptible to exposure during opportunity assessment by partners prior to significant investment and continuing awareness of parental cultural differences once underway. In contrast, symmetric projects seemed to show more inclination for each participating business, not wishing to imply criticism/distrust of an organisation owning comparable influence and commercial standing, to extend partners an assumed similarity of understanding/purpose until conflict symptoms became more evident. While not a general rule, eleventh-hour realisations over basic symmetricventure objectives were not uncommon within the study. For example, one frustrated respondent commented "there needs to be a better understanding of what is meant by innovation"; another highlighted miscommunication over co-creation practice and the need to "give staff a [common] framework" to progress solutions.

There are also additional secondary understandings gleaned from survey outcomes:

\section{Customer satisfaction directly impacts percentage of repeat business}

For XYZ, import of customer satisfaction was never more evident than in the drop in contract renewals leading up to 2012. This was a signal that some projects had imperfect appreciation of the co-creation raison d'être. Analysing renewal metrics against the recent HoR an interesting correlation was made - the danger zone for losing trade was customer satisfaction falling below 60\%. Customer ratings rising above 65\% meant relationships (recurring business) were increasingly safe.

\section{Successful innovation delivery increases customer satisfaction}

When significant innovative outcomes or ideas were visibly delivered by a jointventure then customer satisfaction rose markedly; when only standard efficiencies and process were presented then customers regarded these as a baseline not deserving of a more than average score. Successful innovation, especially of the 
radical and transformational varieties, is clearly a major factor for award of an elevated approval by customer-side co-creation partners.

\section{Innovation co-creation requires building a strategic framework}

Incremental innovation can be progressed via standard processes and mechanisms. However, radical and/or transformational innovations imply networking beyond a single firm for resources, skills and investment. Organisations considering cocreation to develop major innovation must be prepared to redesign (or completely replace) their existing business model if they truly wish to create an experience environment able to best use idea and resource pools.

Choosing the co-creation path in pursuit of transformational innovation seemingly requires a proactive business mindset and willingness to adapt quite different from that dictated by tradition. Examining partner satisfaction appears a useful way of understanding when a refresh of enterprise norms may be needed.

\section{Conclusion}

Re-tuning the business model towards innovation is increasingly a determinant of corporate success yet research indicates that many large established organisations struggle to deliver. Kodak invested over \$5 billion in digital technology and never managed to become more than a small player in that market while Knight Ridder reportedly accumulated losses of over $\$ 100$ million in the launch of its first online newspaper (Koen et al., 2011). Many other examples exist.

To enhance skills and improve products and services, organisations are progressively turning towards collaborative techniques for networking organisational entities (Mooney and Dovey, 2012). Potentially, co-creation of high-value innovation is one of the techniques and customers one of the entity groups.

At the start of this paper we stated that we were interested in exploring:

i) Lessons learned from high-value co-creation initiatives;

ii) The link between customer collaboration and the likelihood of innovation emergence (especially when exercised within a symmetric dynamic).

Reviewing partnering experiences of the 99 engineering services ventures has gone some way to investigating these elements. The study suggests that co-creating is not simply joint-delivery of project outcomes to product or company-centric objectives; rather it crafts a mutual experience, common vision and collective identity for those involved. When the former heuristic was preeminent then incremental-level innovation could be achieved - when the latter was visible then radical and transformational varieties were possible.

This also links to earlier work of Muthusamy et al. (2007), Reuer and Arino (2007) and Schumacher (2006) regarding the nature of strategic alliances. For collaborating entities seeking significant solutions a cultural investment beyond skill and material resource is required. This is best approached from positions where mutual trust, operational familiarity and overlapping philosophy have already been mediated by practice rather than prescribed fiat. Especially for symmetric joint-ventures the prospect of transformational outcomes rises significantly when partners have a longstanding rapport fostering a strategic relationship. Alternatively, revolutionary results have less likelihood, often defaulting back to incremental levels, when the partnership 
bond is less progressed and depth of connection between parent organisations still developing.

Approaching innovation co-creation from the initial direction of customer satisfaction also provided additional intriguing insights:

- Differences in perception and/or alignment greater than 5\% between a service provider and customer could signal that a breakdown in partnership is in progress;

- Once a partner's satisfaction rating falls below $60 \%$ then the likelihood of losing them at the next contract review date is high;

- Customer priorities and satisfaction should be tracked iteratively. Comparing assessments over time can provide valuable advance warning of compounding shifts in customer (and market) focus.

One final conclusion of the current research is the value of research itself. Tuning alliances entails new modes of thought (Johnston and Kong, 2011) - or as one respondent described it, realising "[the] mindset to value innovation in its own right...not limit value to what can be sold”. Partnerships and cooperative networking pose their own set of attitudinal challenges and customer satisfaction frameworks appear useful in monitoring such endeavours. Regular exploration of relationship perceptions, direction and communications, at both senior management and practitioner levels, can help reveal misunderstandings and seeds for discontent before they become threats to the collaboration.

For the XYZ/customer joint-ventures the HoR study helped clarify issues of service objectives, innovation expectations and collective alignment enabling XYZ to provide a higher level service offering. It also prompted them to be more selective in forming alliances and to better focus on those partnerships where radical or transformational innovation opportunities could be mutually beneficial.

The research findings in this paper provide useful insights for service sector organisations seeking to engage in co-creation activities. We hope that it may also prompt other academic researchers towards exploring future lines of enquiry around the building of high-value, co-created innovation partnerships.

\section{Acknowledgements}

The authors would like to thank XYZ and their joint-venture partners for their candor in contributing to our research and to the external reviewers for their helpful comments on earlier versions of this paper.

\section{References}

Antikainen, M., Makipaa, M. and Ahonen, M. (2010) "Motivating and supporting collaboration in Open Innovation”, European Journal of Innovation Manaagement, Vol. 13 No 1, pp.100-119.

AON Hewitt (2011a) Trends in Gobal Employee Engagement, AON Hewitt Ltd.

AON Hewitt (2011b) Employee Engagement, Technology and Analytics, Presentation Prepared by Consulting, AON Hewitt Ltd, May, pp. 5.

AON Hewitt (2012) 2012 Trends in Gobal Employee Engagement, AON Hewitt Ltd, London.

Blumenitt, T. (2004) "Does small and mature have to mean dull? Defying the ho-hum at SMEs", Journal of Business Strategy, Vol. 25 No. 1, pp. 27-33. 
Borjesson, S. and Lofsten, H. (2012) “Capabilities for innovation in small firms - a study of 131 hightech firms and their relation to performance”, International Journal of Business Innovation and Research, Vol. 6 No. 2, pp. 149-176.

Buchanan, L. (1992) "Vertical trade relationships: the role of dependence and symmetry in attaining organisational goals”, Journal of Marketing Research, Vol. 29 No. 1, pp.65-75.

Burdon, S., Chelliah, J and Bhalla, A. (2009) “Structuring enduring strategic alliances”, Journal of Business Strategy, Vol. 30 No. 4, pp.42-51.

Chapman, R.L. and Corso, M. (2005) "From continuous improvement to collaborative innovation: the next challenge in supply chain management”, Production Planning and Control, Vol. 16 No. 4, pp.339-344.

Chesbrough, H. W. and Appleyard M.M. (2007) "Open innovation and strategy”, California Management Review, Vol. 50 No. 1, pp. 57-76.

Christensen, C., Raynor, M. and Anthony, S.D. (2003) "Six keys to building new markets by unleashing disruptive innovation”, HBSWK, available at http://hbswk.hbs.edu/item/3374.html (accessed 2 April 2015).

Christensen, C. and Raynor, M. (2003) The Innovator's Solution, Harvard Business School Publishing, Boston.

Czuchry, A.J., Yasin, M.M. and Peisl, T.C. (2009) "A systematic approach to promoting effective innovation: a conceptual framework and managerial implications”, International Journal of Business Innovation and Research, Vol. 3 No. 6, pp.575-595.

Denning, S. (2010) “A leader's guide to radical management of continuous innovation”, Strategy and Leadership, Vol. 38 No. 4, pp.11-16.

Dershin, H. (2010) “A framework for managing innovation“, International Journal of Business Innovation and Research, Vol. 4 No. 6, pp. 598-613.

Desouza, K.C., Awazu, Y., Sanjeev, J., Dombrowski, C., Papagari, S., Baloh, P. and Kim, J.Y. (2008) "Customer-driven innovation to be a marketplace leader: let your customers drive”, ResearchTechnology Management, Vol. 51 No. 3, pp. 35-44.

Dewar, R. D. and Dutton, J.E. (1986) "The adoption of radical and incremental innovation: an empirical analysis”, Management Science, Vol. 32 No. 11, pp. 1422-1433.

Di Gangi, P.M., Wasko, M., Hooker, R. (2010) “Getting customers’ ideas to work for you - learning from Dell how to succeed with online user innovation communities”, MIS Quarterly Executive, Vol. 9 No. 4, pp. 213-228.

Dyer, J.H., Gregersen, H.B. and Christensen, C.M. (2009) “The innovator’s DNA: five discovery skills separate true innovator's from the rest of us”, Harvard Business Review, Vol. 87 No. 12, pp. 60 - 67.

Dyer, J.H., Gregersen, H.B. and Christensen, C.M. (2011) The Innovator's DNA: mastering the five skills of disruptive innovators, Harvard Business School Press, Boston.

Enkel, E., Kausch, C. and Gassmann, O. (2005) “Managing the risk of customer integration”, European Management Journal, Vol. 23 No. 2, pp. 203-213.

Faems, D., Looy, B.V. and Debackere, K. (2005) "Interorganizational collaboration and innovation: toward a portfolio approach”, Journal of Product Innovation Management, Vol. 22 No. 3, pp. 238-250.

Foss, N.J., Laursen, K. and Pedersen, T. (2011) "Linking customer interaction and innovation: the mediating role of new organizational practices”, Organization Science, Vol. 22 No. 4, pp. 980999.

Foster, R. and Kaplan, S. (2001) Creative Destruction, Doubleday Publishing, New York.

Gebauer, H., Johnson, M, and Enquist, B. (2010) "Value co-creation as a determinant of success in public transport services: a study of the Swiss federal railway operator (SBB)", Managing Service Quality, Vol. 20 No. 6, pp. 511-530.

Giesen, E., Riddleberger, E., Christner, R and Bell, R. (2010) "When and how to innovate your business model”, Strategy and Leadership, Vol. 38 No. 4, pp. 17-26.

Grabher, G., Ibert, O. and Flohr, S. (2008) "The neglected king: the customer in the new knowledge ecology of innovation”, Economic Geography, Vol. 84 No. 3, pp. 253-280.

Gumusluoglu, L. and Ilsev, A. (2009) “Transformational leadership, creativity and organizational innovation”, Journal of Business Research, Vol. 62 No. 4, pp. 461-473. 
Hansen, M.T. (2009) "When internal collaboration is bad for your company", Harvard Business Review, Vol. 87 No. 4, pp. 82-88.

Jaruzelski, B., Loehr J. and Holman, R. (2011) “Global innovation 1000: why culture is key”, Strategy + Business, Booz \& Co., Vol 65, available at http://www.strategy-business.com/article/11404 (Accessed 2 August 2013).

Johnston, R. and Kong, X. (2011) “The customer experience: a road-map for improvement”, Managing Service Quality, Vol. 21 No. 1, pp. 5-24.

Juga, J., Juntunen, J. and Grant, D. (2010) "Service quality and its relation to satisfaction and loyalty in logistics outsourcing relationships”, Managing Service Quality, Vol. 20 No. 6, pp. 496-510.

Koen, A., Bertels, H.M. and Elsum, I. (2011) "The three faces of business model innovation: challenges for established firms”, Research-Technology Management, Vol. 54 No. 3, pp. 5259.

Kumar, N., Scheer, L. and Steenkamp, J. (1995) “The effects of perceived interdependence on dealer attitudes”, Journal of Marketing Research, Vol. 32 No. 3, pp.348-356.

Lendrum, T. (2000) The Strategic Partnering Handbook: The Practitioner's Guide to Partnerships and Alliances, McGraw-Hill, Sydney.

Lewrick, M. and Raeside, R. (2010) "Transformation and change process in innovation models: startup and mature companies”, International Journal of Business Innovation and Research, Vol. 4 No. 6, pp. 515-534.

Mentzer, J., Min, S. and Zacharia, Z. (2000) "The nature of interfirm partnering in supply chain management”, Journal of Retailing, Vol. 76 No. 4, pp.549-568.

Mooney, G. and Dovey, K. (2012) "Leadership practices in the generation and deployment of intangible capital resources for innovation”, International Journal of Intellectual Capital, Vol. 9 No. 3, pp. 295-306.

Muthusamy, S. and White, M. (2005) "Learning and knowledge transfer in strategic alliances: a social exchange view”, Organization Studies, Vol. 26 No. 3, pp. 416-441.

Muthusamy, S., White, M. and Carr, A. (2007) "An empirical examination of the role of social exchanges in alliance performance”, Journal of Managerial Issues, Vol. 19 No. 1, pp. 53-75.

Mustak, M., Jaakkola, E. and Halinen, A. (2013) "Customer participation and value creation: a systematic review and research implications”, Managing Service Quality, Vol. 23 No. 4, pp. 341-359.

Nair, A. and Boulton W.R. (2008) "Innovation-oriented operations strategy typology and stage-based model”, International Journal of Operations and Production Management, Vol. 28 No. 8, pp. 748-771.

Payne, A.F., Storbacka, K. and Frow, P. (2008) "Managing the co-creation of value”, Journal of the Academy of Marketing Science, Vol. 36 No. 1, pp. 83-96.

Piperopoulos, P. and Scase, R. (2009) "Competitiveness of small and medium sized enterprises: towards a two dimensiohnal model of innovation and business clusters”, International Journal of Business Innovation and Research, Vol. 3 No. 5, pp. 479-499.

Prahalad, C.K. and Ramaswamy, V. (2004a) The Future of Competition: Co-Creating Unique Value with Customers, Harvard Business Press Books, Boston.

Prahalad, C.K. and Ramaswamy, V. (2004b) "Co-creation experiences: the next practice in value creation”, Journal of Interactive Marketing, Vol. 18 No. 3, pp.5-14.

Remneland-Wikhamn, B. (2011) "Path dependence as a barrier for 'Soft' and 'Open' innovation”, International Journal of Business Innovation and Research, Vol. 5 No. 6, pp. 714-730.

Reuer, J. and Arino, A. (2007) "Strategic alliance contracts: dimensions and determinants of contractual complexity”, Strategic Management Journal, Vol. 28 No. 3, pp.313-330.

Sampson, S.E. and Spring, M. (2012) "Customer roles in service supply chains and opportunities for innovation”, Journal of Supply Chain Management, Vol. 48 No. 4, pp.30-50.

Schumacher, C. (2006) “Trust - A source of success in strategic alliances?”, Schmalenbach Business Review, Vol. 58 No. 3, pp259-278..

Vaccaro, A., Parente, R. and Veloso, F. M. (2010) "Knowledge management tools, inter-organizational relationships, innovation and firm performance”, Technological Forecasting \& Social Change, Vol. 77 No. 1, pp. 1076-1089. 
Vermeulen, F., Puranam, P. and Gulati, R. (2010) “Change for change’s sake”, Harvard Business Review, Vol. 88 No. 6, pp. 70-76.

$\mathrm{Xu}, \mathrm{L}$. and Bearnon, B. (2006) "Supply chain coordination and cooperation mechanisms: an attributebased approach”, Journal of Supply Chain Management, Vol. 42 No. 1, pp. 4-12.

Waychal, P., Mohanty, R.P. and Verma, A. (2011) "Determinants of innovation as a competence: an empirical study”, International Journal of Business Innovation and Research, Vol. 5, No. 2, pp. 192-211. 